\title{
Toxicity and Antimicrobial Activities of Ionic Liquids with Halogen Anion
}

\author{
You Yu, Yi Nie
}

College of Chemistry and Chemical Engineering, Qufu Normal University, Qufu, China. Email: ny1968@163.com.

Received January $2^{\text {nd }}, 2011$; revised February $18^{\text {th }}, 2011$; accepted March $24^{\text {th }}, 2011$.

\begin{abstract}
To investigate the eco-toxicity of ionic liquids (ILs), experiments on growth of three kinds of bacteria were carried out for six common ILs with halogen anion by a micro-calorimetric method at $310 \mathrm{~K}$. The results indicate that the growth of all the bacteria was inhibited in the presence of ILs. In addition, all ILs at definite concentrations show some toxicity to Escherichia coli, Staphylococcus aureus and Bacillus subtilis. Anti-microbial activities of the ILs with halogen anion are strongly related to structures of the ILs. An increase in alkyl group chain length corresponds with an increase in toxicity, and the ILs with pyridinium cation exhibit stronger restraining effect than the same series ILs with imidazolium cation.
\end{abstract}

Keywords: Toxicity, Ionic Liquids, Inhibition

\section{Introduction}

Ionic liquids (ILs) were applied in many fields such as biological and chemical reactions for they are nonflammable, sparsely volatile and thermally stable. For these properties, air pollution was prevented greatly. However, release of ILs into aquatic environments may lead to water pollution because of their high solubilities.

In recent years, some reports that risks of ionic liquids have been available in environment and organisms. Li Xiaoy et al. [1-5] studied the toxicity of ionic liquids to Daphnia magna. The results showed that the toxicity to Daphnia magna increased with the increasing of $n$-alkyl chain length. Zhang Feng et al. [6] carried out standard test methods for evaluating the toxicity of chemicals to three aquatic organisms. The results indicated that the inhibiting effects increased significantly with increasing concentrations of ILs. In addition, large-scale application, ILs released into the environments will be inevitable. These cause environmental and agricultural pollution. Some reports $[7,8]$ on the germination rate of seeds and growth of seedlings have indicated different seeds have different reaction to ILs which shown eco-toxicity. Moreover, it is dangerous that poisoning organisms can be increased by increasing the food chain. The food chain of primary producers, primary consumers and predators cause acute and chronic toxicity or cancer. So studying the toxicity of ILs is important.

Microcalorimetry was confirmed to be valid as an al- ternative method in the study of metabolism of the cell. [9]. It is a useful tool for investigating the biological processes because it permits the continuous monitoring of the activity of a living process in situ without disturbing the system, and the heat evolved or adsorbed is strictly proportional to the rate of the biological processes [10,11]. With its abundant thermodynamic and kinetic information, micro-calorimetry has been widely applied in clinical analysis, pharmacology, ecology, biotechnology and agriculture $[12,13]$.

In this paper, the effects of common ILs with Halogen anion (as shown in Scheme 1) on Escherichia coli (E. coli), Staphylococcus aureus (S. aureus) and Bacillus subtilis (B. sutilis) growth were investigated by microcalorimetry, and the bacterial growth rate constants $\mu$ at different concentrations (c) of ILs aqueous solutions were calculated via power-time curves along with the generalized Logistic equation. The $\mu-c$ correlation equations were formulated. The results indicate antimicrobial activities are related to the structures of ILs, indicating a potential eco-toxicity of the ILs to the micro-organisms in the water.

\section{Theory}

The growth of bacteria is often limited by some external constraints, including substrate, product concentration, temperature, $\mathrm{pH}$-values and so on. In the logarithmic growth phase, the number of bacteria and time are related according to $[14,15]$ : 


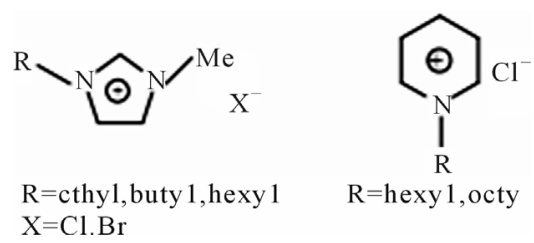

Scheme 1. Chemical structures of prepared Ils.

$$
\frac{d N_{t}}{d t}=\mu N_{t}-\beta N_{t}^{2}
$$

where $N_{t}$ represents the number of bacteria at time $(t), \mu$ is the growth rate constant, $\beta$ is the deceleration rate constant, and $t$ is the experimental time.

By integrating Equation (1) with respect to time $(t)$, the following equation was obtained:

$$
N_{t}=K /\left(1+\alpha e^{-\mu t}\right)
$$

$K(K=\mu / \beta)$ in Equation (2) represents the maximum bacterial number during the whole bacterial growth, and $\alpha$ is the final multiple of the initial bacterial number (being the integral constant).

Under the assumption that the heat production rate $P_{t}$ is proportional to the bacterial number, and $P_{0}$ represents the heat production rate by one bacterium, then,

$$
P_{t}=P_{0} N_{t}, P_{m}=K P_{0}
$$

Inserting it into Equation (2), the following equation was obtained:

$$
P_{t}=P_{m} K /\left(1+\alpha e^{-\mu t}\right)
$$

$P_{m}$ in Equation (3) is the maximum heat production rate during the whole bacterial growth.

Using the experimental data $P_{t}$ and $t$ obtained from the power-time curves, the growth rate constant $(\mu)$ can be calculated by Equation (3).

\section{Experimental and Material}

\subsection{Instrument}

A thermometric eight channel Thermal Activity Monitor (3114/3236TAM Air, Sweden) in conjunction with the operating and analytical software was used in this experiment. With this instrument, reactions can be studied at any given temperature in the temperature range of $5^{\circ} \mathrm{C}$ - $60^{\circ} \mathrm{C}$ within $\pm 2 \times 10^{-2 \circ} \mathrm{C}$ uncertainty. The system is very sensitive, its detection limit is $1 \times 10^{-5} \mathrm{~W}$, and the baseline stability (over a period of $24 \mathrm{~h}$ ) is $2 \times 10^{-5} \mathrm{~W}$. The measuring range contains between $60 \mathrm{~mW}$ and 600 $\mathrm{mW}$. The maximum sample volume is $24 \mathrm{~mL}$.

\subsection{Materials}

Standard strains of E. coli, S. aureus and B. subtilis were used as the test organism.

The beef culture medium was used, containing $1 \mathrm{~g}$
$\mathrm{NaCl}, 2 \mathrm{~g}$ peptone and $1 \mathrm{~g}$ beef extract in every $200 \mathrm{~mL}$. The $\mathrm{pH}$ of medium was adjusted to $7.2-7.4$ before autoclaving. The culture medium was sterilized in high pressure steam at $121^{\circ} \mathrm{C}$ for $30 \mathrm{~min}$ before experiments.

Ionic liquids with halide anion used in this experiment were synthesized according to the published method [16-17]. Aqueous solutions of ILs at different concentrations were prepared using doubly distilled water.

\subsection{Experimental Method}

Ampoule mode was used in this experiment. The bacterial suspension with a volume of $8 \mathrm{~mL}$ was poured into each $24 \mathrm{~mL}$ glass ampoule in sterile conditions. After adding ILs aqueous solution at different concentrations into the ampoule, the ampoules were then sealed with caps and placed into channels. Power-time curves of continuous bacterial growth were recorded by computer. When the baseline was re-established and became stabilized, the process of bacterial growth was complete.

The micro-calorimeter was controlled at $310 \mathrm{~K}$ by thermostat in the whole process, which is the optimum growth temperature.

\section{Results and Discussion}

\subsection{Power-Time Curves of Bacterial Growth}

All ILs with halogen anion were tested for antimicrobial activities against E. coli, S. aureus and B. subtilis. The power-time curves of bacterial growth at $310 \mathrm{~K}$ in the absence and presence of ILs have been determined, and parts of the fit curves in logarithmic growth phase are plotted in Figure 1. It can be seen that the slopes of exponential growth phase at different IL concentrations are different. It can be concluded that the bacterial growth phase changes with adding the ILs aqueous solution into the culture medium.

\subsection{Bacterial Growth Rate Constants}

The data of $P_{t}$ and $t$ were obtained from Figure 1. According to Equation (3), the bacterial growth rate constants $(\mu)$ were calculated, and shown in Tables 1-3. The growth rate constants $(\mu)$ of the E. coli, S. aureus and $B$. subtilis gradually decrease with the increase of the IL concentration $(c)$. This is mainly attributed to the inhibitory effect of the halide ILs to some cells in the bacteria suspension. The survivors remain metabolizing continuously at a lower level of heat production rate, depending on the concentration of IL in the solution.

\subsection{Growth Rate Constants VS Concentrations and Structure of ILs}

The growth rate constants decrease with the increase of IL concentrations. The results indicate that the ILs with 
Table 1. Growth rate constants $\mu / \mathrm{min}^{-1}$ of $E$. Coli at different concentrations of ILs at $310 \mathrm{~K}$.

\begin{tabular}{|c|c|c|c|c|c|c|c|}
\hline ILs & & & & & & & \\
\hline \multirow{2}{*}{ EMIMCl } & $\mathrm{c}(\mathrm{mmol} / \mathrm{L})$ & 4.985 & 7.431 & 16.924 & 25.123 & 30.001 & 39.617 \\
\hline & $\mu\left(\min ^{-1}\right)$ & 0.06029 & 0.05459 & 0.045 & 0.04277 & 0.03509 & 0.02689 \\
\hline \multirow{2}{*}{ BMIMCl } & $c(\mathrm{mmol} / \mathrm{L})$ & 1.44 & 9.132 & 11.133 & 13.784 & 18.084 & \\
\hline & $\mu\left(\min ^{-1}\right)$ & 0.06456 & 0.05515 & 0.04788 & 0.04211 & 0.03701 & \\
\hline \multirow{2}{*}{ HMIMCl } & $c(\mathrm{mmol} / \mathrm{L})$ & 0.537 & 0.892 & 1.422 & 1.773 & 2.122 & 2.643 \\
\hline & $\mu\left(\min ^{-1}\right)$ & 0.05583 & 0.04861 & 0.04152 & 0.03558 & 0.02063 & 0.01481 \\
\hline \multirow{2}{*}{$\mathrm{HPyCl}$} & $c(\mathrm{mmol} / \mathrm{L})$ & 0 & 0.646 & 1.288 & 1.928 & 3.197 & \\
\hline & $\mu\left(\min ^{-1}\right)$ & 0.09126 & 0.0768 & 0.04322 & 0.03798 & 0.01876 & \\
\hline \multirow{2}{*}{$\mathrm{OPyCl}$} & $c(\mathrm{mmol} / \mathrm{L})$ & 0 & 0.235 & 0.352 & 0.584 & 0.699 & \\
\hline & $\mu\left(\min ^{-1}\right)$ & 0.09126 & 0.07036 & 0.04481 & 0.0341 & 0.02268 & \\
\hline \multirow{2}{*}{ BMIMBr } & $c(\mathrm{mmol} / \mathrm{L})$ & 0 & 3.491 & 6.947 & 13.757 & 20.435 & 26.985 \\
\hline & $\mu\left(\min ^{-1}\right)$ & 0.09126 & 0.08043 & 0.07743 & 0.06148 & 0.0582 & 0.03734 \\
\hline
\end{tabular}

Table 2. Growth rate constants $\mu / \mathrm{min}^{-1}$ of $S$. aureus at different concentrations of ILs at $310 \mathrm{~K}$.

\begin{tabular}{|c|c|c|c|c|c|c|c|c|}
\hline ILs & & & & & & & & \\
\hline \multirow{2}{*}{ EMIMCl } & $c(\mathrm{mmol} / \mathrm{L})$ & 0 & 1.508 & 2.508 & 3.998 & 4.985 & 5.967 & 8.885 \\
\hline & $\mu\left(\min ^{-1}\right)$ & 0.10048 & 0.07313 & 0.06869 & 0.05495 & 0.04731 & 0.03729 & 0.0259 \\
\hline \multirow{2}{*}{$\mathrm{BMIMCl}$} & $c(\mathrm{mmol} / \mathrm{L})$ & 0 & 1.44 & 2.155 & 2.866 & 3.574 & \multicolumn{2}{|c|}{4.278} \\
\hline & $\mu\left(\min ^{-1}\right)$ & 0.10048 & 0.07859 & 0.05113 & 0.04211 & 0.04367 & \multicolumn{2}{|c|}{0.03254} \\
\hline \multirow{2}{*}{ HMIMCl } & $c(\mathrm{mmol} / \mathrm{L})$ & 0 & 0.178 & 0.529 & 0.701 & 0.87 & \multicolumn{2}{|c|}{1.038} \\
\hline & $\mu\left(\min ^{-1}\right)$ & 0.10048 & 0.09172 & 0.07211 & 0.06802 & 0.03621 & \multicolumn{2}{|c|}{0.02643} \\
\hline \multirow{2}{*}{$\mathrm{HPyCl}$} & $c(\mathrm{mmol} / \mathrm{L})$ & 0 & 0.0646 & 0.129 & 0.256 & 0.32 & \multicolumn{2}{|c|}{0.477} \\
\hline & $\mu\left(\min ^{-1}\right)$ & 0.10048 & 0.09299 & 0.0827 & 0.0677 & 0.05613 & \multicolumn{2}{|c|}{0.03075} \\
\hline \multirow{2}{*}{$\mathrm{OPyCl}$} & $c(\mathrm{mmol} / \mathrm{L})$ & 0 & 0.0235 & 0.0352 & 0.0468 & 0.0584 & & \\
\hline & $\mu\left(\min ^{-1}\right)$ & 0.10048 & 0.05 & 0.03573 & 0.03095 & 0.0271 & & \\
\hline \multirow{2}{*}{ BMIMBr } & $c(\mathrm{mmol} / \mathrm{L})$ & 0 & 4.358 & 6.947 & 8.662 & 12.913 & & \\
\hline & $\mu\left(\min ^{-1}\right)$ & 0.10048 & 0.09307 & 0.07162 & 0.06862 & 0.05074 & & \\
\hline
\end{tabular}

Table 3. Growth rate constants $\mu / \mathrm{min}^{-1}$ of $B$. subtilis at different concentrations of ILs at $310 \mathrm{~K}$.

\begin{tabular}{|c|c|c|c|c|c|c|c|}
\hline ILs & & & & & & & \\
\hline \multirow{2}{*}{ EMIMCl } & $c(\mathrm{mmol} / \mathrm{L})$ & 0 & 2.508 & 4.985 & 9.848 & 14.594 & \\
\hline & $\mu\left(\min ^{-1}\right)$ & 0.11248 & 0.09984 & 0.0799 & 0.06637 & 0.0472 & \\
\hline \multirow{2}{*}{ BMIMCl } & $c(\mathrm{mmol} / \mathrm{L})$ & 0 & 1.798 & 3.574 & 5.327 & 7.06 & 8.771 \\
\hline & $\mu \quad\left(\min ^{-1}\right)$ & 0.11248 & 0.10884 & 0.09289 & 0.07786 & 0.06444 & 0.04914 \\
\hline \multirow{2}{*}{ HMIMCl } & $c(\mathrm{mmol} / \mathrm{L})$ & 0 & 0.716 & 2.844 & 5.286 & 7.005 & 8.703 \\
\hline & $\mu\left(\min ^{-1}\right)$ & 0.11248 & 0.09693 & 0.0766 & 0.04609 & 0.03397 & 0.01186 \\
\hline \multirow{2}{*}{$\mathrm{HPyCl}$} & $c(\mathrm{mmol} / \mathrm{L})$ & 0 & 0.646 & 1.288 & 1.928 & 2.564 & 3.197 \\
\hline & $\mu\left(\min ^{-1}\right)$ & 0.11248 & 0.10393 & 0.0887 & 0.07373 & 0.06781 & 0.05921 \\
\hline \multirow{2}{*}{$\mathrm{OPyCl}$} & $c(\mathrm{mmol} / \mathrm{L})$ & 0 & 0.59 & 1.177 & 1.693 & 2.342 & \\
\hline & $\mu\left(\min ^{-1}\right)$ & 0.11248 & 0.09185 & 0.08533 & 0.0607 & 0.03813 & \\
\hline \multirow{2}{*}{ BMIMBr } & $c(\mathrm{mmol} / \mathrm{L})$ & 0 & 1.625 & 3.229 & 4.814 & 6.379 & 9.454 \\
\hline & $\mu\left(\min ^{-1}\right)$ & 0.11248 & 0.09181 & 0.07963 & 0.0712 & 0.06419 & 0.03972 \\
\hline
\end{tabular}




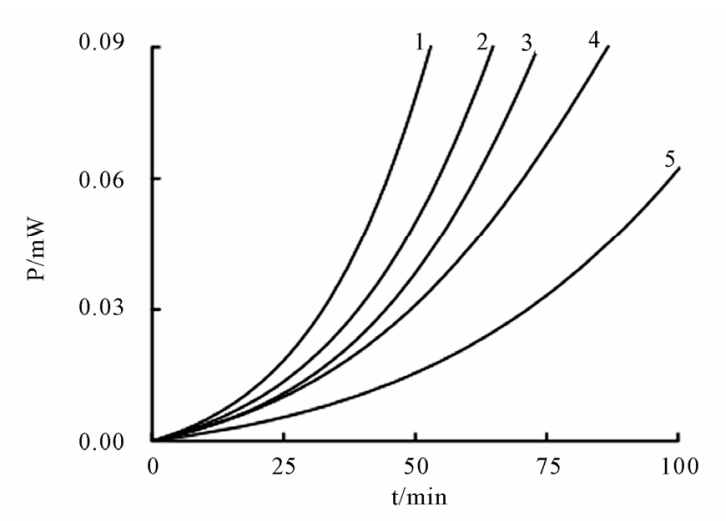

(a)The power-time curves of E.coli at different concentrations of EMIMCI (1)7.41 mmol/L; (2) $16.924 \mathrm{mmol} / \mathrm{L}$; (3) $25.123 \mathrm{mmol} / \mathrm{L}$; (4) $30.001 \mathrm{mmol} / \mathrm{L} ;(5) 39.617 \mathrm{mmol} / \mathrm{L}$

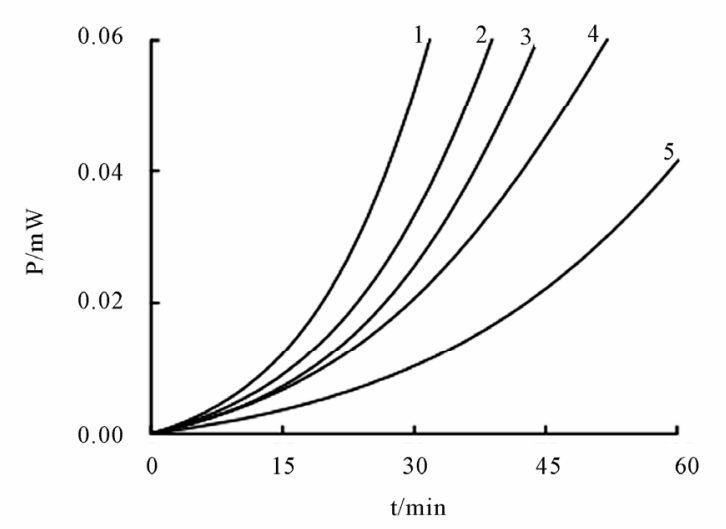

(b)The power-time curves of S.aureus at different concentrations of HMIMCI (1) $0.178 \mathrm{mmol} / \mathrm{L} ;(2) 0.529 \mathrm{mmol} / \mathrm{L}$; (3) $0.701 \mathrm{mmol} / \mathrm{L} ;(4) 0.87 \mathrm{mmol} / \mathrm{L} ;(5) 1.038 \mathrm{mmol} / \mathrm{L}$

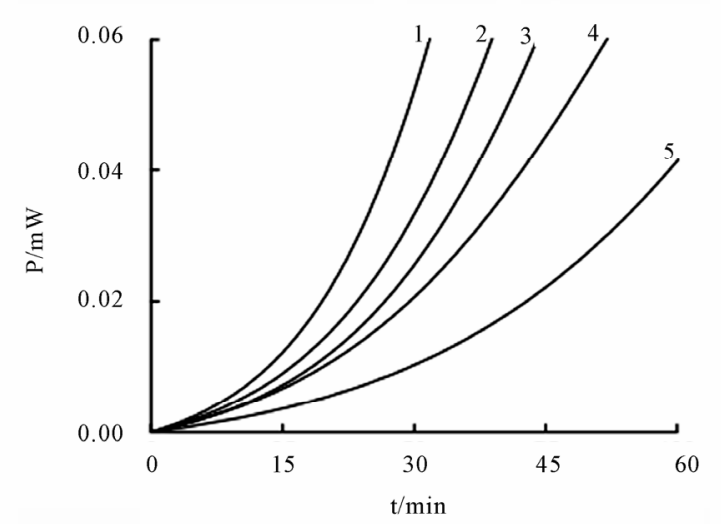

(c)The power-time curves of B.subtilis at different concentrations of $\mathrm{HPyCl}(1) 0 \mathrm{mmol} / \mathrm{L}$; (2) $0.646 \mathrm{mmol} / \mathrm{L}$;

(3) $1.288 \mathrm{mmol} / \mathrm{L} ;(4) 1.928 \mathrm{mmol} / \mathrm{L} ;(5) 2.564 \mathrm{mmol} / \mathrm{L}$

Figure 1. The power-time curves of $E$. coli, $S$. aureus and $B$. subtilis at different ionic liquid concentrations in logarithmic growth phase at $310 \mathrm{~K}$.

halogen anion show significant inhibition to E. coli, $S$. aureus and $B$. subtilis growth. Moreover, their activities are greatly affected by the alkyl chain length of the cation ring, and variety of the cation.

For example, the growth rate constants of E. coli in the presence of ILs follow the order: [BMIM]Br > $[\mathrm{EMIM}] \mathrm{Cl}>[\mathrm{BMIM}] \mathrm{Cl}>[\mathrm{HMIM}] \mathrm{Cl}$. With the same anion $\mathrm{Cl}^{-}$, the longer the alkyl chain length of the imidazolium ring is, the lower the bacterial growth rate constant is. And with the same cation [BMIM] $]^{+}$, the growth rate constant in the presence of [BMIM] $\mathrm{Br}$ is higher than $[\mathrm{BMIM}] \mathrm{Cl}$. The growth rate constants of $B$. subtilis in the presence of ILs follow the order: [HMIM]Cl > $[\mathrm{HPy}] \mathrm{Cl}>[\mathrm{OPy}] \mathrm{Cl}$. With the same anion, the toxicity of pyridinium ring is stronger than that of the imidazolium ring. The inhibitory activity of $[\mathrm{OPy}] \mathrm{Cl}$ is the highest among all ILs.

All $\mu-c$ relationship can be well represented by equations, as listed in Table 4. The correlations between $\mu$ and $c$ of E. coli, $S$. aureus were formulated by quadratic equations, and the correlations between $\mu$ and $c$ of $B$. subtilis were formulated by linear equations. The results suggest all ILs may have the same inhibition mechanism on the E. coli, S. aureus and B. subtilis growth.

\subsection{Inhibition Mechanism}

E. coli, S. aureus and B. subtilis are significantly inhibited by the IL-treatments. The toxic effect of ILs may be related to a common cellular structure or process. It is assumed that the toxicity mechanism of ILs is through interaction with the cell wall and membrane, leading to a membrane disruption [18]. ILs consisting of cation-anion pairs is similar to the structure of surfactants, pesticides and antibiotics that attack lipid structure, and induce polar narcosis due to their interfacial properties, and may cause membrane-bound protein disruption [19]. Moreover, disruption to cell membrane is related to the alkyl chain length of the cation ring and variety of the cation of ILs.

\subsection{Conclusions}

The effects of six halide ionic liquids on the bacterial growth were studied by microcalorimetry. The ionic liquids studied show inhibition activities on the metabolism of E. coli, S. aureus and B. subtilis, and may follow the same inhibition mechanism on the bacteria growth. The antimicrobial activities of ILs are associated with the alkyl side chain length of cation and the variety of the cation. With the same anion, the longer the alkyl side chain length of cation is, the stronger the antibacterial activitie of the IL is. The toxicity of pyridinium ring is stronger than that of the imidazolium ring. The microcalorimetry can be effectively used to study the microbial growth and toxic properties of ILs. The antimicrobial effects of ILs should be considered in their potential 
Table 4. $\mu-c$ correlation equations.

\begin{tabular}{|c|c|c|c|}
\hline bacteria & Ionic liquids & & \\
\hline \multirow{6}{*}{ E.coli } & {$[\mathrm{EMIM}] \mathrm{Cl}$} & $\mu=1.74 \times 10^{-6} c^{2}-9.76 \times 10^{-4} c+0.0633$ & $R^{2}=0.9738$ \\
\hline & {$[\mathrm{BMIM}] \mathrm{Cl}$} & $\mu=-1.22 \times 10 c-1.50 \times 10 c+0.0672$ & $R^{2}=0.9708$ \\
\hline & {$[\mathrm{HMIM}] \mathrm{Cl}$} & $\mu=5.70 \times 10^{-4} c^{2}-0.0179 c+0.0650$ & $R^{2}=0.9974$ \\
\hline & {$[\mathrm{BMIM}] \mathrm{Br}$} & $\mu=-5.16 \times 10^{-6} c^{2}-1.69 \times 10^{-3} c+0.0890$ & $R^{2}=0.9662$ \\
\hline & {$[\mathrm{HPy}] \mathrm{Cl}$} & $\mu=5.30 \times 10^{-3} c^{2}-0.0403 c+0.0936$ & $R^{2}=0.9679$ \\
\hline & {$[\mathrm{OPy}] \mathrm{Cl}$} & $\mu=4.70 \times 10^{-2} c^{2}-0.132 c+0.0924$ & $R^{2}=0.9684$ \\
\hline \multirow{6}{*}{ S. aureus } & [EMIM]Cl & $\mu=6.30 \times 10^{-4} c^{2}-0.0137 c+0.0979$ & $R^{2}=0.9873$ \\
\hline & {$[\mathrm{BMIM}] \mathrm{Cl}$} & $\mu=2.24 \times 10^{-3} c^{2}-0.0258 c+0.102$ & $R^{2}=0.9519$ \\
\hline & {$[\mathrm{HMIM}] \mathrm{Cl}$} & $\mu=-4.78 \times 10^{-2} c^{2}-0.0226 c+0.0993$ & $R^{2}=0.9702$ \\
\hline & {$[\mathrm{BMIM}] \mathrm{Br}$} & $\mu=-6.52 \times 10 c-3.22 \times 10 c+0.102$ & $R=0.9575$ \\
\hline & {$[\mathrm{HPy}] \mathrm{Cl}$} & $\mu=-5.93 \times 10^{-2} c^{2}-0.118 c+0.100$ & $R^{2}=0.9986$ \\
\hline & {$[\mathrm{OPy}] \mathrm{Cl}$} & $\mu=24.9 c^{2}-2.69 c+0.100$ & $R^{2}=0.9983$ \\
\hline \multirow{6}{*}{ B. subtilis } & {$[\mathrm{EMIM}] \mathrm{Cl}$} & $\mu=-2.99 \times 10^{-5} c+0.109$ & $R^{2}=0.973$ \\
\hline & {$[\mathrm{BMIM}] \mathrm{Cl}$} & $\mu=-7.57 \times 10^{-3} c+0.118$ & $R^{2}=0.981$ \\
\hline & {$[\mathrm{HMIM}] \mathrm{Cl}$} & $\mu=-1.11 \times 10^{-2} c+0.108$ & $R^{2}=0.9929$ \\
\hline & {$[\mathrm{BMIM}] \mathrm{Br}$} & $\mu=-7.20 \times 10^{-3} c+0.107$ & $R^{2}=0.9769$ \\
\hline & {$[\mathrm{HPy}] \mathrm{Cl}$} & $\mu=-1.73 \times 10^{-2} c+0.112$ & $R^{2}=0.9673$ \\
\hline & {$[\mathrm{OPy}] \mathrm{Cl}$} & $\mu=-3.06 \times 10^{-2} c+0.114$ & $R^{2}=0.9716$ \\
\hline
\end{tabular}

industrial applications and overall risk assessment.

\section{Acknowledgements}

Shandong Province Natural Scientific Foundation of China (ZR2009BM035), and Shandong Province Science Research Reward Foundation for Excellent Young and Middle-aged Scientists (2008BS02021).

\section{REFERENCES}

[1] X. Li, Y. Luo, L. Li, J. Wang and Z. Sun, "Effects of the Ionic Liquid 1-Methyl 3-Octylimidazolium Bromide on the Feeding Intensity of Daphnia Magna," Acta Scientiae Circumstantiae, Vol. 28, No. 11, November 2008, pp. 2331-2335.

[2] Y. Luo, X. Li, P. Huang, J. Wang and Z. Sun, "Effect of Ionic Liquids with Different Alkyl Chain Lengths on Feeding Behavior of Daphnia Magna," Chinese Journal of Applied and Environmental Biology, Vol. 14, No. 3, June 2008, pp. 383-387.

[3] B. Zhang, Y. Luo and H. Fang, "The Acute Toxicity of 1 Methyl-3-Octylimidazolium Bromide to Daphnia Magna at Different Developmental Stages," Ecology and Envirronment, Vol. 17, No. 3, May 2008, pp. 1021-1023.

[4] R. J. Bernot, M. A. Brueseke, M. A. Evans-White and G.
A. Lamberti, "Acute and Chronic Toxicity of Imidazolium-Based Ionic Liquids on Daphnia Magna," Environmental Toxicology and Chemistry, Vol. 24, No.1, January 2005, pp. 87-92 doi:10.1897/03-635.1

[5] T. P. T. Pham, C. W. Cho, K. Vijayaraghavan, J. Min and Y. S. Yun, "Effect of Imidazolium-Based Ionic Liquids on the Photosynthetic Activity and Growth Rate of Selenastrum Capricornutum," Environmental Toxicology and Chemistry, Vol. 27, No.7, July 2008, pp. 1583-1589. doi:10.1897/07-415.1

[6] H. Mu, X. Peng and F. Zhang, "Toxicity of $\left[\mathrm{C}_{8} \mathrm{mim}\right] \mathrm{PF}_{6}$ to Aquatic Organisms," China Environmental Science, Vol. 29, No. 11, November 2009, pp. 1196-1201

[7] F. Yang, H. Meng, C. Li and Z. Wang, "Ecotoxicity of Ionic Liquids on the Germination and Growth of Three Seeds," Chinese Journal of Environmental Engineering, Vol. 3, No. 4, April 2009, pp. 751-754

[8] P. Liu, L. Sun, H. Liu, K. Xu, Y. Ding, X. Li and J. Wang, "Effects of 1-Octyl-3-Methyl Imidazolium Bromide Ionic Liquid on the Germination and Growth of Wheat Seedlings," Journal of Agro-Environment Science, Vol. 27, No. 2, March 2008, pp. 425-429.

[9] L. N. Yang, F. Xu, L. X. Sun, Z. C. Tan, H. D. Tan, Z. B. Zhao and J. G. Liang, "'Study on Interaction between 
Antibiotics and Escherichia Coli DH5A by Microcalorimetric Method," Journal of Thermal Analysis and Calorimetry, Vol. 85, No. 3, September 2006, pp. 807-810.doi:10.1007/s10973-006-7507-4

[10] L. Núñez-Regueira, J. A. Rodríguez-Añón, J. ProupínCastiñeiras and O. Núñez-Fernández, "Microcalorimetric Study of Changes in the Microbial Activity in a Humic Cambisol after Reforestation with Eucalyptus in Galicia (NW Spain)," Soil Biology and Biochemistry, Vol. 38, No. 1, January 2006, pp. 115-124. doi:10.1016/j.soilbio.2005.04.031

[11] J. C. Zhu, C. H. Li, Y. Liu, Z. H. Zhang, A. X. Hou and S. S. Qu, "A Microcalorimetric Study of the Action of Mercuric Chloride on the Metabolism of Mitochondria Isolated from Cyprinus Carpio Liver Tissue," Journal of Thermal Analysis and Calorimetry, Vol. 83, No. 1, January 2006, pp. 181-186. doi:10.1007/s10973-005-7020-1

[12] J. Ma, W. T. Qi, L. N. Yang, W. T. Yu, Y. B. Xie, W. Wang, X. J. Ma, F. Xu and L. X. Sun, "Microcalorimetric Study on the Growth and Metabolism of Microencapsulated Microbial Cell Culture," Journal of Microbiological Methods, Vol. 68, No. 1, January 2007, pp. 172-177. doi:10.1016/j.mimet.2006.07.007

[13] H. K. Koblish, S. Zhao, C. F. Franks, R. R. Donatelli, R. M. Tominovich, L. V. LaFrance, K. A. Leonard, J. M. Gushue, D. J. Parks, R. R. Calvo, K. L. Milkiewicz, J. J. Marugán, P. Raboisson, M. D. Cummings, B. L. Grasberger, D. L. Johnson, T. Lu, C. J. Molloy and A. C. Maroney, "Benzodiazepinedione Inhibitors of the Hdm2:P53 Complex Suppress Human Tumor Cell Proliferation in Vitro and Sensitize Tumors to Doxorubicin in Vivo," Molecular Cancer Therapeutics, Vol. 5, No. 1, January 2006, pp. 160-169.

\section{doi:10.1158/1535-7163.MCT-05-0199}

[14] H. L. Zhang, H. T. Sun, Z. D. Nan and Y. J. Liu, "Establishment of Experimental Model of Bacterial Growth under Inhibitory Conditions and Study of Optimum Growth Temperature," Journal of Thermal Analysis, Vol. 44, No. 1, January 1995, pp. 105-109.

[15] H. L. Zhang, X. F. Yu, X. X. Li and X. R. Pan, "A Study of Promotive and Fungistatic Actions of Steroidal Saponin by Microcalorimetric Method," Thermochimica Acta, Vol. 416, No. 1-2, June 2004, pp. 71-74. doi:10.1016/i.tca.2003.11.033

[16] T. Nishida, Y. Tashiro and M. Yamamoto, "Physical and Electrochemical Properties 1-Alkyl-3-Methylimidazolium Tetrafluoroborate for Electrolyte," Journal of Flu- orine Chemistry, Vol. 120, No. 2, April 2003, 135-141.doi:10.1016/S0022-1139(02)00322-6

pp.

[17] Y. H. Zhu, C. B. Ching, K. Carpenter, R. Xu, S. Selvaratnam, N. S. Hosmane and J. A. Maguire, "Synthesis of the Novel Ionic Liquid [ $N$-pentylpyridinium $]^{+}$ [Closo- $\left.\mathrm{CB}_{11} \mathrm{H}_{12}\right]^{-}$and Its Usage as a Reaction Medium in Cata- lytic Dehalogenation of Aromatic Halides," Applied Organometallic Chemistry, Vol. 17, No. 6-7, June-July 2003, pp. 346-350.doi:10.1002/aoc. 407

[18] K. M. Docherty and C. F. Kulpa. "Toxicity and Antimicrobial Activity of Imidazolium and Pyridinium Ionic Liquids," Green Chemistry, Vol. 7, No. 4, March 2005, pp. 185-189. doi:10.1039/b419172b

[19] R. J. Bernot, E. E. Kennedy and G. A. Lamberti, "Effects of Ionic Liquids on the Survival, Movement, and Feeding Behavior of the Freshwater Snail, Physa Acuta," Environmental Toxicology and Chemistry, Vol. 24, No. 7, July 2005, pp. 1759-1765. doi:10.1897/04-614R.1 